\title{
THE ERYTHROCYTE SEDIMENTATION RATE AND THE PLASMA VISCOSITY
}

\author{
BY \\ ROBERT D. EASTHAM \\ From the Department of Clinical Pathology, University College Hospital, London
}

(RECEIVED FOR PUBLICATION SEPTEMBER 29, 1953)

Certain factors are common to the erythrocyte sedimentation rate and the plasma viscosity. Thus fibrinogen increases the erythrocyte sedimentation rate (Gram, 1921; Greisheimer, Johnson, and Ryan, 1929) and Hardwicke, Ricketts, and Squire (1950) found that a direct logarithmic relation exists between the erythrocyte sedimentation rate and the plasma fibrinogen concentration. Also fibrinogen exerts the greatest effect of the plasma protein fractions, weight for weight, on the plasma viscosity (Naegeli, 1931). Globulin increases the sedimentation rate but not to the same extent as does fibrinogen, weight for weight (Ley, 1922 ; Linzenmeier, 1923 ; Fåhraeus, 1929) ; similarly, globulin exerts a greater effect than albumin and a lesser effect than fibrinogen, weight for weight, on the plasma viscosity. That the plasma viscosity is affected mainly by the plasma proteins and only slightly influenced by the non-protein constituents is known (Naegeli, 1931 ; Cowan and Harkness, 1947), and Miller and Whittington (1942) state that the plasma viscosity can be taken as an index of the power of the plasma to cause red cell aggregation and rouleaux formation. Whittington (1942) was able to correlate the maximum erythrocyte sedimentation rate with the plasma viscosity and the whole blood viscosity. (This latter value is affected by the degree of the red cell aggregation.) Thus the plasma proteins have a significant effect on both the erythrocyte sedimentation rate and the plasma viscosity. Many hydrophilic colloids besides plasma are capable of causing red cell aggregation with increased rates of sedimentation: these include gum acacia, gelatin, agar agar, and casein solutions (Fåhraeus, 1929), and Hardwicke and Squire (1952) showed that the concentrations of macromolecules, such as fibrinogen, dextrans, gelatin, gum acacia, and polyvinyl pyrrolidone bore a linear relation to the maximum erythrocyte sedimentation rate. Also, they showed that the degree of the effect on the maximum erythrocyte sedimentation rate varied with the size of the macromolecules.
Comparing the maximum erythrocyte sedimen-o tation rate of various blood samples, at a constant $i$ v haematocrit value of $45 \%$, with their correspond ing plasma viscosity values, it was found that out $\AA$ of 99 results, 96 showed a direct correlation be-음 tween the maximum erythrocyte sedimentationrates and the plasma viscosity values, but three 3 blood samples with very high plasma viscosity values had much slower maximum erythrocyte $\vec{\bullet}$ sedimentation rates than was expected. The possible reasons for this disparity were examined.

\section{Methods}

A. Blood, $10 \mathrm{ml}$., was taken from each of $99 \stackrel{2}{\circ}$ patients and normal controls into $0.1 \mathrm{ml}$. of a solution containing $6 \mathrm{~g}$. ammonium oxalate and $4 \mathrm{~g}$. potassium $\underset{ }{\rightleftharpoons}$ oxalate in $100 \mathrm{ml}$. (Lawrence, 1950). The haemoglobino level, packed cell volume, and mean corpuscular 3 haemoglobin concentration were estimated. Then in 55 samples the maximum erythrocyte sedimentation? rates were observed in a $200 \mathrm{~mm}$. column of $2-5 \mathrm{~mm}$. internal bore, by plotting the fall of the red cello columns every three minutes. The maximum rates of $\frac{O}{3}$ fall were corrected from the chart of Rourke and. Ernstene (1930) to correspond to the maximum ratesô of fall at a packed cell volume of $45 \%$. In the remaining 44 samples, the packed cell volume waso adjusted to $45 \%$ by removing or adding plasma, and the maximum erythrocyte sedimentation rates wereo derived by plotting the fall of the red cell columns every three minutes.

The plasma specific gravity was estimated (Harrison, 1947) and finally the plasma viscosity was estimated at $25^{\circ} \mathrm{C}$. by the method described byc Lawrence (1950).

From the data obtained, namely, the whole bloodo haemoglobin concentration, the packed cell volume and the plasma specific gravity, the red cell specifices? gravity was calculated, using the formula of Phillips et al. (1945) quoted by Harrison (1947).

B. Samples of blood, each of $20 \mathrm{ml}$., were taken from a normal person into $0.2 \mathrm{ml}$. of the oxalatep mixture used in experiment A. After washing twice in the final suspending fluid, the red cells were re suspended at a packed cell volume of $45 \%$ in various 


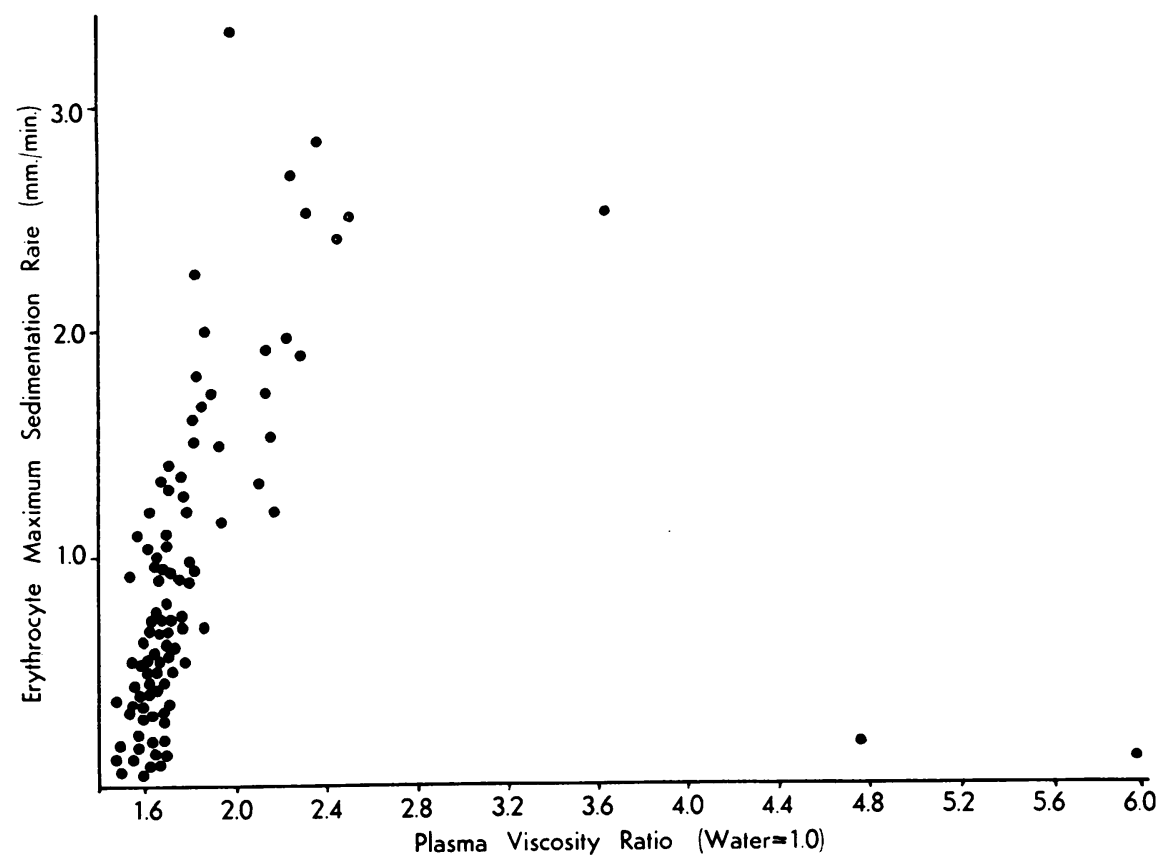

Fig. 1.-The maximum sedimentation rate of 99 samples of blood plotted against their corresponding plasma viscosity ratios. The packed cell volume was adjusted in each case to $45 \%$

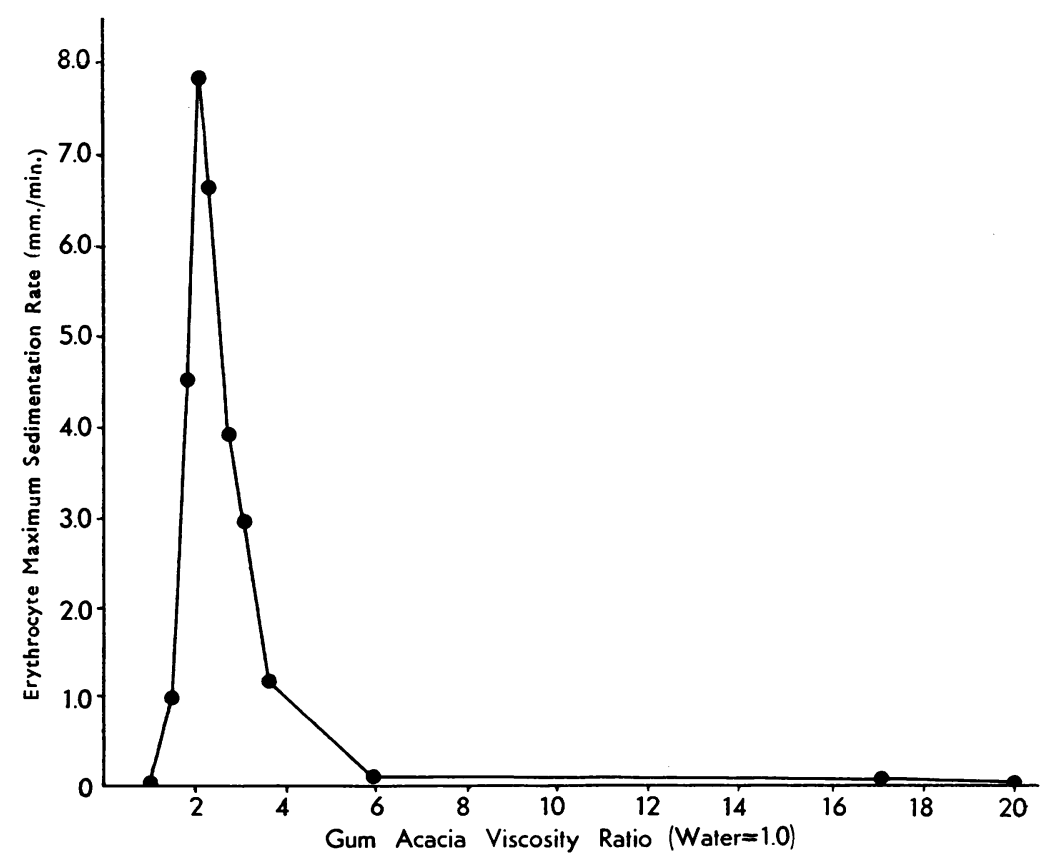

FIG. 2.-The maximum sedimentation rate of red cells suspended in various dilutions of gum acacia at a packed cell volume of $45 \%$. 
dilutions of (a) gum acacia in physiological saline, (b) polyvinyl pyrrolidone in isotonic solution ("plasmosan," May and Baker), (c) dextran in physiological saline ("dextraven," Benger).

These red cell suspensions were left at room temperature for 30 minutes and then the maximum erythrocyte sedimentation rate of each sample was plotted by reading the height of the red cell column in $200 \mathrm{~mm}$. tubes every three minutes.

\section{Results}

Of the 99 blood samples shown in Fig. 1 in which the maximum erythrocyte sedimentation rate is plotted against the corresponding plasma viscosity, 96 show an increase of the maximum erythrocyte sedimentation rate corresponding to the increase of the plasma viscosity. No simple relation could be found to exist between these two factors, although an empirical formula was developed.

Thus plasma viscosity $=a+b . \quad V$, (maximum erythrocyte sedimentation rate) where $\mathrm{V}=\frac{\text { (specific gravity difference between red cell }}{\text { (maxis }}$ and plasma)

and the constants $(\mathrm{a}=1.531, \mathrm{~b}=0.0161)$.

The variance about the line is 0.01621 . If the variance of the values of the plasma viscosity is the same at all values of $\mathrm{V}$, then $95 \%$ of the plasma viscosity ratio values will lie within a range of 0.253 on either side of the line. In other words, the estimation of the plasma viscosity from the maximum erythrocyte sedimentation rate, or vice versa, is only very approximate. It was also found that although variations in specific gravity difference between erythrocyte and plasma was allowed for, it did not appear to increase the precision of the estimation to any great extent.

The results of three blood samples fell well outside the line of the other 96 results in Fig. 1. These three showed a much slower maximum sedimentation rate proportional to the plasma viscosity than the others. All three were samples taken from cases of multiple myelomatosis with very high plasma protein concentrations, particularly plasma globulins, and correspondingly very high plasma viscosity values.

It can be seen from Figs. 2, 3, and 4 that gum acacia, polyvinyl pyrrolidone, and dextran greatly influence the sedimentation rate. In each solution, as the concentration increases, the maximum erythrocyte sedimentation rate also increases, until a peak is reached. From this point, as the concentration and, hence, viscosity of the solution in-

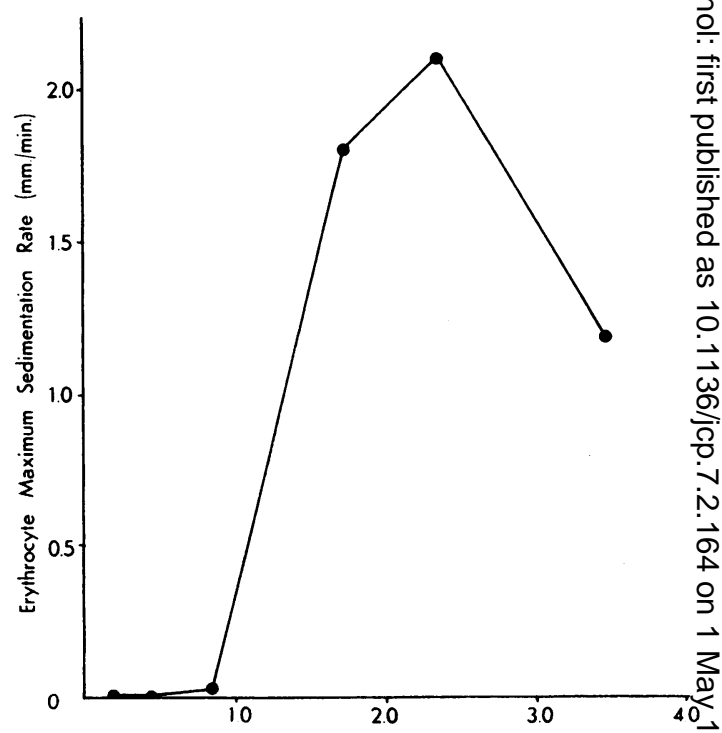

Concentration of Polyvinyl Pyrrolidone \% in Physiological Saling

FIG. 3.-The maximum sedimentation rate of red cells suspended ił various dilutions of polyvinyl pyrrolidone at a packed cell volume of $45 \%$.

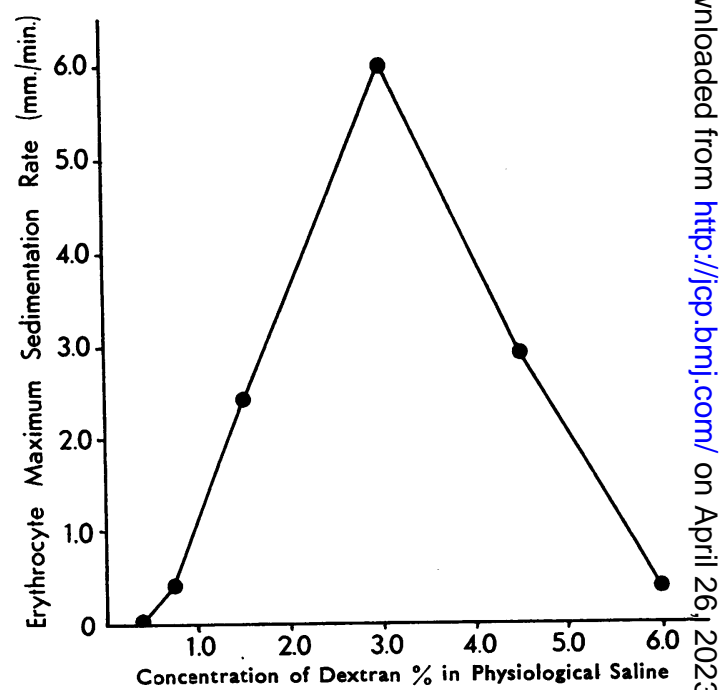

Fig. 4.-The maximum sedimentation rate of red cells suspended in various dilutions of dextran at a packed cell volume of $45 \%$.

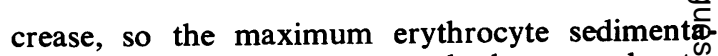
tion rate decreases to approach the normal rates for erythrocyte suspended in plasma $(0.08 \mathrm{~mm}$ min., Rourke and Ernstene, 1930).

\section{Discussion}

It is suggested that the three blood samples 通 Fig. 1 which lie outside the rough line formed $8 y$ 
the other 96 specimens are in fact specimens in which the plasma viscosity is so great that, although red cell aggregation is intense (confirmed by examination of wet films), the fall of the aggregate is impeded by the viscosity of the fluid.

That this is possible may be seen in Figs. 2, 3, and 4 . These figures show that as the viscosity of the three solutions increases, so at first does the maximum erythrocyte sedimentation rate until a maximum rate of sedimentation is reached. Beyond this peak, increase in the viscosity of each solution is accompanied by progressive decrease in the maximum rate of sedimentation. Wet films of the red cells in these solutions revealed the presence of intense aggregation, and in the sedimentation tubes the cell columns appeared granular. This granular appearance is common in rapidly sedimenting samples if the columns are viewed in a bright light.

While the erythrocyte sedimentation rate is a useful and easily performed test for changes in the plasma proteins in disease, it is suggested that in some cases in which the plasma viscosity is greatly increased the plasma viscosity is a much better clinical test. Hardwicke and Squire (1952) found a direct correlation between the maximum erythrocyte sedimentation rate and the plasma viscosity, but the highest value for the plasma viscosity ratio relative to water was 2.65 . Of the 99 blood samples examined in experiment A, 96 had plasma viscosity ratios ranging between 1.47 and 2.65 and the three outstanding blood samples had plasma viscosity ratios of $3.65,4.77$, and 5.96 respectively.

Thus the plasma proteins and the three other hydrophilic colloids, dextran, acacia, and polyvinyl pyrrolidone, affect the erythrocyte sedimentation rate in two ways; first, by stimulating the formation of large aggregates they increase the sedimentation rate, and secondly, by increasing the plasma viscosity they impede the fall of the aggregates and hence slow the sedimentation rate. It has been shown that either action may overshadow the other, depending on the concentration and viscosity of the colloidal solution. It is suggested that any attempt to correlate the plasma viscosity and the erythrocyte sedimentation rate should allow for this.

\section{Summary}

Hydrophilic colloids, such as gum acacia, polyvinyl pyrrolidone, dextran, and plasma proteins, accelerate the erythrocyte sedimentation rate by stimulating red cell aggregation, and also diminish the erythrocyte sedimentation rate by their viscosity slowing the rate of fall of the red cell aggregation.

Which of these two actions of the colloid preponderates is determined by the viscosity value of the solution. As the viscosity of the solution of colloid rises, so the erythrocyte sedimentation rate increases until a point is reached, beyond which any increase in the viscosity of the solution depresses the erythrocyte sedimentation rate.

The significance of these findings is discussed in relation to attempts to relate the erythrocyte sedimentation rate and the plasma viscosity quantitatively.

The specific gravity difference between the red cell and the plasma probably does not exert much effect on the erythrocyte sedimentation rate.

I am grateful to Professor M. Maizels for his encouragement and helpful criticism, and to Dr. J. S. Eawrence for the loan of a viscometer of his design. Also I am indebted to Mr. W. Please, of the Department of Statistics, for the development of the empirical formula.

\section{REFERENCES}

Cowan, I. C., and Harkness, J. (1947). Brit. med. J., 2, 686. Fåhraeus, R.' (1929). Physiol. Rev., 9, 241.

Gram, H. C. (1921). Arch. intern. Med., 28, 312.

Greisheimer, E. M., Johnson, O. H., and Ryan, M. (1929). Amer. J. med. Sci., 177, 816.

Hardwicke, J., Ricketts, C. R., and Squire, J. R. (1950). Nature, Lond., 166, 988.

- and Squire, J. R. (1952). Clin. Sci., 11, 333.

Harrison, G. A. (1947). Chemical Methods in Clinical Medicine, 3rd ed. Churchill, London.

Lawrence, J. S. (1950). Journal of Clinical Pathology, 3, 332.

Ley, R. (1922). Z. ges. exp. Med., 26, 59.

Linzenmeier, G. (1923). Münch. med. Wschr., 70, 1243.

Miller, A. K., and Whittington, R. B. (1942). Lancet, 2, 510.

Maegeli, O. (1931). Blutkrankheiten und Blutdiagnostik, 5th ed.

Springer, Berlin.

Whittington, R. B. (1942). Proc. roy. Soc. B., 131, 183. 